\title{
Evolution in Overcoming Barriers in Management of Diabetes: Hypoglycemia
}

\author{
Sonal S. Banzal ${ }^{1}$, Subodh Banzal ${ }^{2}$, Udaya M. Kabadi ${ }^{3,4}$ \\ ${ }^{1}$ Index Medical College Hospital and Research Centre, Indore, India \\ ${ }^{2}$ Shri Aurobindo Institute of Medical Sciences and PG Institute, Indore, India \\ ${ }^{3}$ Broadlawns Medical Center, Des Moines, Iowa, USA \\ ${ }^{4}$ University of Iowa, Iowa City, Iowa, USA \\ Email: *sonalbanzal9@gmail.com
}

How to cite this paper: Banzal, S.S., Banzal, S. and Kabadi, U.M. (2021) Evolution in Overcoming Barriers in Management of Diabetes: Hypoglycemia. Journal of Diabetes Mellitus, 11, 234-248.

https://doi.org/10.4236/jdm.2021.115020

Received: October 2, 2021

Accepted: November 13, 2021

Published: November 16, 2021

Copyright $\odot 2021$ by author(s) and Scientific Research Publishing Inc. This work is licensed under the Creative Commons Attribution International License (CC BY 4.0).

http://creativecommons.org/licenses/by/4.0/

\begin{abstract}
The main objective of management of diabetes focuses on eliminating symptoms of hyperglycemia, preventing hyperglycemic and other metabolic complications, delaying onset of chronic deleterious microvascular disorders and reducing macrovascular risk. However, iatrogenic hypoglycemia remains a major limiting factor in attaining and maintaining desirable glycemic targets. Hypoglycemia is defined as plasma glucose concentration $<70 \mathrm{mg} / \mathrm{dl}$ exposing the individual to potential harm. Hypoglycemia is classified into level 1 being asymptomatic or symptomatic documented by blood sugar $54-69$ $\mathrm{mg} / \mathrm{dl}$; level 2 with blood sugar $<54 \mathrm{mg} / \mathrm{dl}$ irrespective of symptoms and level 3 or "severe" requiring secondary assistance for resuscitation. Initial symptoms of hypoglycemia are attributed to catecholamine release whereas more serious manifestations are caused by neuroglycopenia. Moreover, nocturnal hypoglycemia and hypoglycemia unawareness present serious consequences including death. The most important goal is to identify patients at a high risk of hypoglycemia, patient education to be on alert for circumstances provoking hypoglycemia and modify treatment regimen based upon individual characteristics. Strategies to manage hypoglycemia are divided into 3 broad categories: 1) Prevention of hypoglycemia, 2) Use of novel technology such as self-blood glucose monitoring systems, insulin pumps, insulin auto injectors as well as newer therapeutic agents including regimens with low/no occurrence of hypoglycemia, and 3) Education of patients and caregivers in treatment of hypoglycemia e.g. use of oral glucose as well as use of glucagon kits.
\end{abstract}

\section{Keywords}

Diabetes, Hypoglycemia, Recognition, Prevention, Treatment 


\section{Introduction}

The role of achieving desirable glycemic control in improving quality of life by eliminating symptoms of hyperglycemia as well as preventing acute metabolic and/or delaying micro and macro vascular complications in people with diabetes is well established [1]-[7]. However, iatrogenic hypoglycemia remains a major limiting factor in attaining and maintaining near normal glycemic indices [1]. Hypoglycemia is defined as abnormally low plasma or blood glucose concentration less than $70 \mathrm{mg} / \mathrm{dl}$ with a potential of exposing the individual to harm. Classification of iatrogenic hypoglycemia in subjects with diabetes has evolved over the last several years (Table 1).

Table 1. Changing guidelines for classification of hypoglycemia [8].

\begin{tabular}{|c|c|}
\hline \multicolumn{2}{|c|}{ Classification of hypoglycemia } \\
\hline \multicolumn{2}{|c|}{ American Diabetes Association Workgroup on Hypoglycemia - 2005 report } \\
\hline Category & Criteria \\
\hline Severe & $\begin{array}{l}\text { Symptoms requiring active assistance of another person to treat. } \\
\text { Is independent of blood glucose }\end{array}$ \\
\hline $\begin{array}{l}\text { Documented } \\
\text { symptomatic }\end{array}$ & Symptoms with a measured low plasma glucose, self-treated \\
\hline Asymptomatic & No typical symptoms but, a measured low plasma glucose \\
\hline Probable symptomatic & $\begin{array}{l}\text { Symptoms typical of hypoglycemia, not accompanied by a } \\
\text { plasma glucose determination }\end{array}$ \\
\hline Pseudo/Relative & $\begin{array}{l}\text { Typical symptoms of hypoglycemia with a measured PG } \\
\text { concentration }>70 \mathrm{mg} / \mathrm{dl}\end{array}$ \\
\hline \multicolumn{2}{|c|}{ Canadian Diabetes Association 2013: Hypoglycemia Clinical Practice Guidelines } \\
\hline Category & Criteria \\
\hline Severe & $\begin{array}{l}\text { Individual requires assistance of another person. } \\
\text { Unconsciousness may occur. } \mathrm{PG}<50 \mathrm{mg} / \mathrm{dl}\end{array}$ \\
\hline Moderate & $\begin{array}{l}\text { Autonomic and neuroglycopenic symptoms are present. The } \\
\text { individual is able to self-treat }\end{array}$ \\
\hline Mild & $\begin{array}{l}\text { Autonomic symptoms are present. The individual is able to } \\
\text { self-treat }\end{array}$ \\
\hline
\end{tabular}

American Diabetes Association Standards of Medical Care in Diabetes 2017

\begin{tabular}{lll}
\hline Level & Glycaemic Criteria & Description \\
\hline $\begin{array}{l}\text { Glucose alert value } \\
\text { (Level 1) }\end{array}$ & $\begin{array}{l}\text { Sufficiently low for treatment with } \\
\text { fast-acting carbohydrate and dose } \\
\text { adjustment of glucose-lowering therapy }\end{array}$ \\
$\begin{array}{l}\text { Clinically significant } \\
\text { hypoglycemia (Level 2) }\end{array}$ & $\begin{array}{l}\text { Sufficiently low to indicate serious, } \\
\text { clinically important hypoglycemia }\end{array}$ \\
$\begin{array}{l}\text { Severe hypoglycemia } \\
\text { (Level 3) }\end{array}$ & $\begin{array}{l}\text { No specific glucose } \\
\text { threshold }\end{array}$ & $\begin{array}{l}\text { Hypoglycemia associated with severe } \\
\text { cognitive impairment requiring external } \\
\text { assistance for recovery }\end{array}$ \\
\hline
\end{tabular}




\section{Clinical Manifestations of Iatrogenic Hypoglycemia}

\subsection{Type 1 Diabetes}

Hypoglycemia is an inevitable event in patients with type 1 diabetes. Patients with type 1 diabetes have an especially high rate of occurrence of hypoglycemia with almost $3 \%-4 \%$ of deaths being attributed to this dangerous side effect [5]-[15].

Asymptomatic hypoglycemia is a frequent side effect especially in type $1 \mathrm{di}$ abetes with almost up to $10 \%$ of patients unknowingly suffering through it with a fall in plasma glucose reaching as low as $<50 \mathrm{mg} / \mathrm{dl}(2.8 \mathrm{mM} / \mathrm{l})$ [5] [10] [11] [15]. Continuous Glucose Monitoring System (CGMS) documented an average of two episodes of symptomatic hypoglycemia per week and 1 - 2 episodes of severe and temporarily disabling, hypoglycemia approximately once a year requiring hospitalization in subjects with both types receiving multiple daily doses of insulin [2] [12] [13]. Thus, hypoglycemia has become a "matter of fact" of life especially in type 1 diabetes with occurrence of thousands of episodes throughout their lifetime.

\subsection{Type 2 Diabetes}

Fortunately, the incidence of hypoglycemia is significantly lower during the initial stage of the disease in patients with type 2 diabetes when compared with subjects with type 1 diabetes. However, with the progression of the disease with gradual descent towards being insulin deficient, hypoglycemic events become more frequent due to exogenous insulin administration required for treatment owing to chronic escalating insulin deficiency [16]-[22]. Fortunately though, even with vigorous insulin therapy, the rates of severe hypoglycemia in type 2 diabetes are approximately about $10 \%$ of those in type 1 diabetes and range from nearly 62 - 170 episodes per 100 patient years [1] [2] [5] [11] [12] [13] [15] [20] [21] [23].

\subsection{Manifestations of Hypoglycemia}

Symptoms of Hypoglycemia are divided into 2 groups:

1) Induced by catecholamine or cholinergine release: jitters, shakiness, drenching sweats, palpitations, hunger, paresthesias, systolic hypertension etc. 2) Neuroglycopenic symptoms due to neuronal glucose deprivation activating autonomic nervous system responses and limiting neuronal metabolism [5] [22] [23] [24] [25]. They include sensations of warmth, weakness, fatigue, difficulty in concentration, confusion, behavioral changes, irritability and emotional instability. However, the most serious neuroglycopeinic include confusion, convulsion, coma and occasionally death. Symptoms in group 1 often precede the more serious manifestations in group 2. Catecholamine mediated symptoms are thought to be related to the rapidity of fall in blood sugar and usually manifest with blood sugar falling below $70 \mathrm{mg} / \mathrm{dl}$ whereas neuroglycopenic manifestations often occur with blood sugar levels $<54 \mathrm{mg} / \mathrm{dl}$. 
Nocturnal hypoglycemia is suspected with presence of nightmares and/ or night sweats followed by headache, fatigue, confusion on awakening associated with rebound hyperglycemia (Somogyi effect). Determination of blood sugar level with self-blood glucose monitoring equipment is recommended to document the presence of hypoglycemia with onset of aforementioned symptoms followed by oral or parenteral administration of glucose for resuscitation.

Prior to advent of point of care blood glucose testing devices, hypoglycemia was suspected in all subjects with diabetes on onset of typical manifestations especially a change in mental status or loss of consciousness. Glucose was administered without confirmation of low blood sugar often with remission of symptoms. Moreover, deleterious outcomes were rarely noted on administration of glucose in subjects with diabetes with obtundation secondary to other causes. In contrast, occasionally, neuroglycopenic symptoms were attributed to neurological disorders, e.g. seizure, stroke etc. thus delaying the diagnosis and treatment with detrimental outcomes.

\section{Diagnostic Criteria for Hypoglycemia}

Whipple's triad is diagnostic and includes symptoms compatible with hypoglycemia confirmed by documentation of low plasma or blood glucose concentration and resolution of symptoms after ingestion or intravenous administration of glucose resulting in raised or normal blood sugar concentration. The triad holds well since the availability of point of contact glucose testing. Subjects with diabetes of moderate duration readily recognize onset of hypoglycemia even though the symptoms and signs of hypoglycemia are nonspecific. Hence it's crucial for the newly diagnosed diabetic patients to keep a regular record and monitoring of their low glucose levels coinciding with the onset of symptoms [5]. Since glucose levels less than $70 \mathrm{mg} / \mathrm{dl}$ can hamper defenses against subsequent hypoglycemia, we recommend provision of self-blood glucose testing kits to all subjects with diabetes irrespective of type as well as prescribed drugs.

\section{Consequences of Hypoglycemia (Table 2)}

Hypoglycemia potentially may result in serious outcomes especially in the elderly as well as all subjects following frequent recurrences.

Table 2. Adverse consequences of hypoglycemia.

$$
\begin{gathered}
\text { Brain death } \\
\text { Ventricular arrhythmia } \\
\text { Non-fatal cardiac events like MI } \\
\text { Motor vehicle and other accidents } \\
\text { Autonomic failure leading to unrecognized hypoglycemia } \\
\text { Stroke } \\
\text { Suboptimal glycemic control } \\
\text { Employment limitations }
\end{gathered}
$$




\section{Pathogenesis of Hypoglycemia in Diabetes}

In normal subjects, initial defense against falling plasma glucose concentrations include the decline in insulin secretion, which decreases utilization of glucose by insulin sensitive tissues such as adipose tissue or skeletal muscle while also promoting hepatic and renal glucose production [1] [5]. Decline in plasma glucose stimulates glucagon secretion which plays a critical role in glucose counter-regulation by facilitating hepatic glycogenolysis and gluconeogenesis. In addition, catecholamines, cortisol and growth hormone are released promptly in response to falling glucose levels and prevent hypoglycemia by enhancing glucose production promptly (within minutes) [1] [5] [15].

A surplus of therapeutic insulin (absolute or relative) especially in association with inadequate food intake and/or exercise is established to lower plasma glucose concentrations into hypoglycemic range in subjects with both type 1 and type 2 diabetes. Hypoglycemia also occurs frequently in subjects with diabetes in presence of renal disease because of exaggerated peaks and longer duration of action due to decline in clearance of exogenous insulin. Rarely, generation of insulin antibodies may contribute to recurrent hypoglycemic events; "Autoimmune hypoglycemia" in subjects receiving insulin for several years [26]. Alternatively, impaired regulation in secretion of all three counter regulatory hormones, exacerbates and perpetuates occurrence of hypoglycemia in subjects with both type 1 and type 2 diabetes [1] [5] [15] [27]-[33].

Aberration of glucagon secretion by pancreatic alpha cells is more pronounced in comparison to other counter regulatory hormones. Glucagon response to declining glucose levels is inhibited, a signaling defect in diabetes of both types though with greater impairment in type 1 diabetes [34] [35] [36] [37] [38]. Fortunately, Glucagon secretory response to stimuli other than hypoglycemia such as amino acid infusion or ingestion of high protein diet is largely, though not entirely preserved [37] [38].

Preserved physiologic regulation of compensatory glucose secretion early in the course of type 2 diabetes is apparently responsible for relatively low frequency of hypoglycemia [1] [5] [39] [40] [41]. However, hypoglycemic events occur more frequently with worsening insulin deficiency secondary to progressive beta cell failure in type 2 diabetes [1] [5] [18] [39] [40]. Recurrent hypoglycemic episodes, eventually impair the hormonal and symptomatic responses to subsequent hypoglycemia and hence raise the threshold for low plasma glucose levels leading to hypoglycemia unawareness [30]. Alternatively, onset of autonomic failure (Figure 1) induced attenuation of sympathetic neural and hormonal as well as adrenomedullary responses to hypoglycemia in long standing diabetes leads to hypoglycemia unawareness with progression to potentially life threatening neuroglycopenic manifestations [1] [15] [39]-[45].

\section{Risk Factors for Hypoglycemia Excess of Insulin}

Absolute or relative excess in circulating insulin due to endogenous production 


\section{Hypoglycemia-Associated Autonomic Failure}

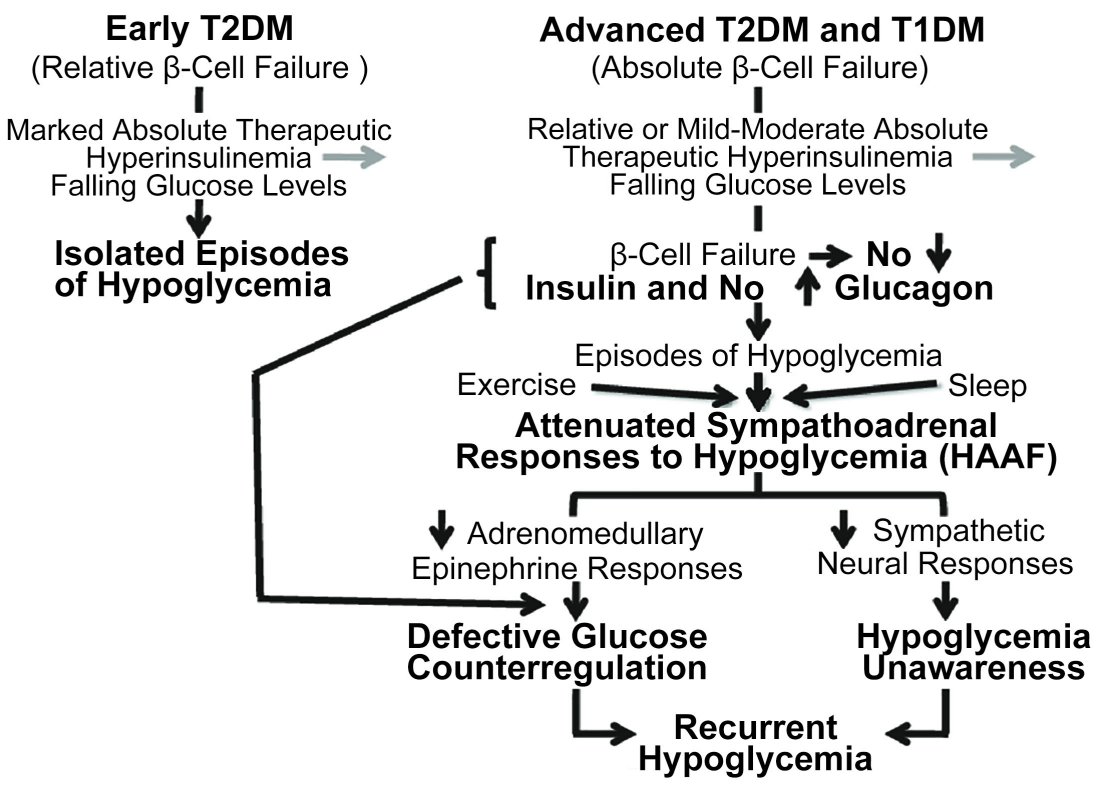

Figure 1. Diagrammatic depiction of hypoglycemia-associated autonomic failure in diabetes [70].

or via exogenous administration has proven to be a major risk factor for hypoglycemia [1] [5] [39] [40] [41]. However enhanced insulin sensitivity induced by drugs and/or exercise as well as increased physical activity also play a critical role in onset of hypoglycemia [3] [4] [44] [45] [46].

The most common cause of hypoglycemia in subjects with diabetes is the absolute or relatively increased circulating insulin concentrations following administration of insulin [47]-[56]. Amongst insulins, rapid acting variety is the most frequent culprits. However, newer analogs have been safer as compared to older prandial insulins [47] [48] [49] [50]. Alternatively, hypoglycemic events ensue during the night or early morning following administration of basal insulins especially at bedtime [51]-[56]. Hypoglycemia also occurs on administration of any insulin being ill timed, or of the wrong type, or if the dose is apparently excessive [47]-[56]. Enhanced insulin secretion following administration of insulin secretagogues contributes to occurrence of hypoglycemia in subjects with type 2 diabetes [3] [4] [45] [46] [47] [57] [58]. Finally, hypoglycemia may occur with overt aggressive glycemic control $(\mathrm{HbA1c}<6.5)$, acute alcohol ingestion, adjuvant therapy with drugs for associated disorders, weight loss, progressive renal failure etc [47] [59] [60] [61] [62] [63]. Thus, the risk factors for hypoglycemia include erratic eating patterns, inappropriate administration of insulin or oral drugs, untimely exercise schedules, overtly aggressive control and most importantly, however unawareness.

Hypoglycemia unawareness is due to absence of manifestations mediated by catecholamine release. Thus, further decline in circulating glucose level ensues leading to life threatening neuroglycopenic manifestations including confusion, 
convulsion and coma. Hypoglycemia unawareness is attributed to autonomic dysfunction, adrenal medullary failure, long duration of diabetes as well as drugs including ACE inhibitors as well as alpha and beta adrenergic blockers [64]-[73].

\section{Treatment of Hypoglycemia}

The foremost and vital aspect in treatment of hypoglycemia is to recognize the high risk patients and then titrate their treatment regimen accordingly. The approach to successfully manage hypoglycemia in subjects with diabetes is diversified into the following tenets:

- Prevention of hypoglycemia

- Use of available therapeutic agents/treatment regimens with low/no occurrence of hypoglycemia

- Treatment of hypoglycemia

Prevention and treatment of hypoglycemia have evolved with improvement in recognition following advent of point of care glucose testing tools, safer insulin formulations as well as oral drugs, individualized desirable glycemic targets based on patient characteristics and availability of diabetes education [45]-[62] [74]-[81]. Until the availability of self-monitoring of blood glucose (SMBG), diagnosis of hypoglycemia was based on symptoms alone. Similarly, the treatment consisted of either oral administration of granulated sugar or sweet liquids if the patient was awake enough to swallow. In presence of a change in mental status, the patient had to be rushed to the hospital for administration of glucose intravenously until glucagon kits were formulated and became available [82]-[87].

With technological advances in SMBG, most episodes of symptomatic hypoglycemia are confirmed by point of care testing and therefore are effectively self-treated by ingestion of glucose in form of granules, tablets or gels. An initial glucose dose of $20 \mathrm{~g}$ is recommended [47] [61] [62]. Alternatively, $4 \mathrm{oz}$. of fruit juice or other sugar containing liquids may be administered. Glucose administration in any form should be repeated in 15 - $20 \mathrm{~min}$ if symptoms persist or the monitored blood sugar remains low. However, the glycemic response to oral glucose is typically short lived usually lasting up to 2 hours [47] [61] [62].

Continuous glucose monitoring systems especially with "alerts" indicating falling glucose trends help prevent occurrences of asymptomatic hypoglycemic events. Moreover, most recent insulin pumps are equipped with the ability to adjust the rate or total suspension of insulin administration on blood sugar falling below the set lowest target of blood glucose [74]-[81]. Thus, home blood glucose monitoring remains a core component of effective diabetes self-management with amelioration of both hyper and hypoglycemia. If a patient manifesting hypoglycemia is unable or unwilling (because of neuroglycopenia) to ingest carbohydrate, glucagon is administered by family members to treat hypoglycemia in type 1 diabetes [82]-[87]. However, in type 2 diabetes the use of glucagon may not be as effective as it stimulates insulin secretion concomitant with glycogenolysis. Glucagon was available only in injectable form until recently when other formulations including glucagon powder for nasal administration were approved by 
Table 3. Guidelines for increasing food intake to allow for extra activity in diabetics on insulin therapy [91].

\begin{tabular}{c}
\hline Activity increase/extra hour of activity (gm/carbohydrate) \\
\hline Moderate activity (e.g,. tennis, cycling, jogging, swimming) \\
$10-15$ \\
Strenuous activity (e.g., shoveling snow, ice hockey, football) \\
$30-50$ \\
\hline
\end{tabular}

regulatory agencies [82]-[87]. Intravenous glucose administration is more effective than glucagon in resuscitating patients with severe hypoglycemia. Nocturnal hypoglycemic events may be avoided by substituting pre-prandial administration of short-acting (regular) insulin by rapid acting insulin analogue (e.g., lispro or aspart) [47] [48] [49] [50]. Similarly, replacing long-acting insulin analogue (e.g., glargine or detemir) for intermediate-acting insulin.

(NPH) may also reduce the frequency of nocturnal hypoglycemia [51]-[56]. Episodes of nocturnal hypoglycemia may be almost totally ameliorated by administration of basal insulin glargine in the morning [55] [56]. Ingestion of a bedtime snack is another effective remedy [88].

Other approaches such as, night-time administration of terbutaline, caffeine, glucagon stimulating amino acid alanine and the slowly digested carbohydrate uncooked cornstarch have been reported though rarely recommended [89] [90]. Finally, exercise induced hypoglycemia can be prevented by appropriate strategies (Table 3).

In conclusion, hypoglycemia and subsequent fear of hypoglycemic episodes are pivotal parameters in diabetes management and can pose a substantial threat to optimal compliance to treatment. Severe hypoglycemia requiring the assistance of another person is a clinical emergency unless the onset is attributed to a remedial variable, such as a missed meal after insulin injection or a vigorous exercise without the appropriate regimen adjustment. A substantive alteration in the treatment regimen may be required to prevent recurrence. Lack of adjustment may result in an unacceptably high risk of recurrent severe hypoglycemia detrimental to life. However, attaining and maintaining desirable glycemic control while minimizing the risk of hypoglycemia has become feasible with advent of technological advances including continuous glucose monitor systems, insulin pumps, safer evolving formulations of insulin as well as newer oral agents and patient education.

\section{Acknowledgements}

Authors are grateful to Sarah Exley for assistance in preparation of the manuscript.

\section{Conflicts of Interest}

The authors declare no conflicts of interest regarding the publication of this paper. 


\section{References}

[1] Cryer, P.E. (2002) Hypoglycaemia: The Limiting Factor in the Glycaemic Management of Type I and Type II Diabetes. Diabetologia, 45, 937-948.

https://doi.org/10.1007/s00125-002-0822-9

[2] The Diabetes Control and Complications Trial Research Group (1993) The Effect of Intensive Treatment of Diabetes on the Development and Progression of Long-Term Complications in Insulin-Dependent Diabetes Mellitus. New England Journal of Medicine, 329, 977-986. https://doi.org/10.1056/NEJM199309303291401

[3] The United Kingdom Prospective Diabetes Study Research Group (1998) Intensive Blood-Glucose Control with Sulphonylureas or Insulin Compared with Conventional Treatment and Risk of Complications in Patients with Type 2 Diabetes (UKPDS 33). Lancet, 352, 837-853. https://doi.org/10.1016/S0140-6736(98)07019-6

[4] The United Kingdom Prospective Diabetes Study Research Group (1998) Effect of Intensive Blood-Glucose Control with Metformin on Complications in Overweight Patients with Type 2 Diabetes (UKPDS 34). Lancet, 352, 854-865.

https://doi.org/10.1016/S0140-6736(98)07037-8

[5] Cryer, P.E. (1997) Hypoglycemia. Pathophysiology, Diagnosis and Treatment. Oxford University Press, New York.

[6] Stratton, I.M., Adler, A.I., Neil, H.A.W., Matthews, D.R., Manley, S.E., Cull, C.A., Hadden, D., Turner, R.C., Holman, R.R. and the UKPDS Research Group (2000) Association of Glycaemia with Macrovascular and Microvascular Complications of Type 2 Diabetes: Prospective Observational Study. BMJ, 321, 405-412. https://doi.org/10.1136/bmj.321.7258.405

[7] Khaw, K.-T., Wareham, N., Luben, R., Bingham, S., Oakes, S., Welch, A. andDay, N. (2001) Glycated Haemoglobin, Diabetes, and Mortality in Men in Norfolk Cohort of European Prospective Investigation of Cancer and Nutrition (EPIC-Norfolk). $B M$ J, 322, Article No. 15. https://doi.org/10.1136/bmj.322.7277.15

[8] Singh, A.K., Talwalkar, P.G., Ahluwalia, A., Modi, K.D. and Modi, K.D. (2018) Expert Group Recommendations on Detection and Management of Hypoglycemia in Routine Clinical Practice in Insulin Treated Patients with Diabetes DEC. The Journal of the Association of Physicians of India, 66, 90-97.

[9] Cryer, P.E. and Childs, B.P. (2002) Negotiating the Barrier of Hypoglycemia in Diabetes. Diabetes Spectrum, 15, 20-27. https://doi.org/10.2337/diaspect.15.1.20

[10] Boland, E., Monsod, T., Delucia, M., Brandt, C.A., Fernando, S. and Tamborlane, W.V. (2001) Limitations of Conventional Methods of Self-Monitoring of Blood Glucose. Diabetes Care, 24, 1858-1862. https://doi.org/10.2337/diacare.24.11.1858

[11] Gross, T.M., Mastrototaro, J.J. and Fredrickson, L.P. (2001) Detection of Unseen Hypoglycemia Using Continuous Glucose Monitoring (Abstract). Diabetologia, 43, Article No. A5.

[12] Reichard, P., Berglund, B., Britz, A., Cars, I., Nilsson, B.Y. and Rosenqvist, U. (1991) Intensified Conventional Insulin Treatment Retards the Microvascular Complications of Insulin-Dependent Diabetes Mellitus (IDDM): The Stockholm Diabetes Intervention Study (SDIS) after 5 Years. Journal of Internal Medicine, 230, 101-108. https://doi.org/10.1111/j.1365-2796.1991.tb00415.x

[13] MacLeod, K.M., Hepburn, D.A. and Frier, B.M. (1993) Frequency and Morbidity of Severe Hypoglycaemia in Insulin-Treated Diabetic Patients. Diabetic Medicine, 10, 238-245. https://doi.org/10.1111/j.1464-5491.1993.tb00051.x

[14] Laing, S.P., Swerdlow, A.J., Slater, S.D., Botha, J.L., Burden, A.C., Waugh, N.R., 
Smith, A.W., Hill, R.D., Bingley, P.J., Patterson, C.C., Qiao, Z. and Keen, H. (1999) The British Diabetic Association Cohort Study. II. Cause-Specific Mortality in Patients with Insulin-Treated Diabetes Mellitus. Diabetic Medicine, 16, 466-471. https://doi.org/10.1046/j.1464-5491.1999.00076.x

[15] Cryer, P.E., Davis, S.N. and Shamoon, H. (2003) Hypoglycemia in Diabetes. Diabetes Care, 26, 1902-1912. https://doi.org/10.2337/diacare.26.6.1902

[16] Abraira, C., Colwell, J.A., Nuttall, F.Q., Sawin, C.T., Nagel, N.J., Comstock, J.P., Emanuele, N.V., Levin, S.R., Henderson, W. and Lee HS. (1995) Veterans Affairs Cooperative Study on Glycemic Control and Complications in Type II diabetes: Results of the feasibility Trial. Diabetes Care, 18, 1113-1123. https://doi.org/10.2337/diacare.18.8.1113

[17] Saudek, C.D., Duckworth, W.C., Giobbie-Hurder, A., Henderson, W.G., Henry, R.R., Kelley, D.E., Edelman, S.V., Zieve, F.J., Adler, R.A., Anderson, J.W., Anderson, R.J., Hamilton, B.P., Donner, T.W., Kirkman, M.S., Morgan, N.A. and the Department of Veterans Affairs Implantable Insulin Pump Study Group (1996) Implantable Insulin Pump vs. Multiple-Dose Insulin for Non-Insulin-Dependent Diabetes Mellitus: A Randomized Clinical Trial. JAMA, 276, 1249-1258.

https://doi.org/10.1001/jama.1996.03540160044031

[18] The United Kingdom Prospective Diabetes Study Group (1995) U.K. Prospective Diabetes Study. 16. Overview of 6 Years' Therapy of Type II Diabetes: A Progressive Disease. Diabetes, 44, 1249-1258. https://doi.org/10.2337/diab.44.11.1249

[19] The United Kingdom Prospective Diabetes Study Research Group (1998) A 6-Year, Randomized, Controlled Trial Comparing Sulfonylurea, Insulin, and Metformin Therapy in Patients with Newly Diagnosed Type 2 Diabetes That Could Not Be Controlled with Diet Therapy. Annals of Internal Medicine, 128, 165-175.

https://doi.org/10.7326/0003-4819-128-3-199802010-00001

[20] Hepburn, D.A., MacLeod, K.M., Pell, A.C., Scougal, I.J. and Frier, B.M. (1993) Frequency and Symptoms of Hypoglycaemia Experienced by Patients with Type 2 Diabetes Treated with Insulin. Diabetic Medicine, 10, 231-237.

https://doi.org/10.1111/j.1464-5491.1993.tb00050.x

[21] Campbell, I.W. (1993) Hypoglycaemia and Type 2 Diabetes: Sulphonylureas. In: Frier, B.M. and Fisher, B.M., Eds., Hypoglycaemia and Diabetes: Clinical and Physiological Aspects, Edward Arnold, London, 387-392.

[22] Gerich, J.E. (1989) Oral Hypoglycemic Agents. New England Journal of Medicine, 321, 1231-1245. https://doi.org/10.1056/NEJM198911023211805

[23] Towler, D.A., Havlin, C.E., Craft, S. and Cryer, P. (1993) Mechanism of Awareness of Hypoglycemia: Perception of Neurogenic (Predominantly Cholinergic) Rather than Neuroglycopenic Symptoms. Diabetes, 42, 1791-1798.

https://doi.org/10.2337/diab.42.12.1791

[24] McAulay, V., Deary, I.J. and Frier, B.M. (2001) Symptoms of Hypoglycaemia in People with Diabetes. Diabetic Medicine, 18, 690-705.

https://doi.org/10.1046/j.1464-5491.2001.00620.x

[25] Boyle, P.J., Schwartz, N.S., Shah, S.D., Clutter, W.E. and Cryer, P.E. (1988) Plasma Glucose Concentrations at the Onset of Hypoglycemic Symptoms in Patients with Poorly Controlled Diabetes and in Nondiabetics. New England Journal of Medicine, 318, 1487-1492. https://doi.org/10.1056/NEJM198806093182302

[26] Huynh, T. (2020) Clinical and Laboratory Aspects of Insulin Autoantibody Mediated Glycaemic Dysregulation and Hyperinsulinaemic Hypoglycaemia: Insulin $\mathrm{Au}$ toimmune Syndrome and Exogenous Insulin Antibody Syndrome. Clinical Biochem- 
ist Reviews, 41, 93-102. https://doi.org/10.33176/AACB-20-00008

[27] Amiel, S.A., Sherwin, R.S, Simonson, D.C. and Tamborlane, W.V. (1988) Effect of Intensive Insulin Therapy on Glycemic Thresholds for Counterregulatory Hormone Release. Diabetes, 37, 901-907. https://doi.org/10.2337/diab.37.7.901

[28] Schwartz, N.S., Clutter, W.E., Shah, S.D. and Cryer, P.E. (1987) Glycemic Thresholds for Activation of Glucose Counterregulatory Systems Are Higher than the Threshold for Symptoms. Journal of Clinical Investigation, 79, 777-781. https://doi.org/10.1172/JCI112884

[29] Mitrakou, A., Ryan, C., Veneman, T., Mokan, M., Jenssen, T., Kiss, I., Durrant, J., Cryer, P. and Gerich, J. (1991) Hierarchy of Glycemic Thresholds for Counterregulatory Hormone Secretion, Symptoms, and Cerebral Dysfunction. American Journal of Physiology - Endocrinology and Metabolism, 260, E67-E74.

https://doi.org/10.1152/ajpendo.1991.260.1.E67

[30] Fanelli, C., Pampanelli, S., Epifano, L., Rambotti, A.M., Ciofetta, M., Modarelli, F., Di Vincenzo, A., Annibale, B., Lepore, M., Lalli, C., Sindaco, P., Brunetti, P. and Bolli, G. (1994) Relative Roles of Insulin and Hypoglycaemia on Induction of Neuroendocrine Responses to, Symptoms of, and Deterioration of Cognitive Function in Hypoglycaemia in Male and Female Humans. Diabetologia, 37, 797-807. https://doi.org/10.1007/BF00404337

[31] Segel, S.A., Paramore, D.S. and Cryer, P.E. (2002) Hypoglycemia-Associated Autonomic Failure in Advanced Type 2 Diabetes. Diabetes, 51, 724-733. https://doi.org/10.2337/diabetes.51.3.724

[32] Kabadi, U.M. (2021) Diabetes Mellitus: Disorder of Cellular Dysfunction Due to Lack of Entry into Cell of Glucose. The Most Efficient Fuel for Cellular Function. Open Journal of Endocrine and Metabolic Diseases, 11, 79-101. https://doi.org/10.4236/ojemd.2021.113007

[33] Dagogo-Jack, S.E., Craft, S. and Cryer, P.E. (1993) Hypoglycemia-Associated Autonomic Failure in Insulin-Dependent Diabetes Mellitus. Journal of Clinical Investigation, 91, 819-828. https://doi.org/10.1172/JCI116302

[34] Gerich, J.E, Langlois, M., Noacco, C., Karam, J.H. and Forsham, P.H. (1973) Lack of Glucagon Response to Hypoglycemia in Diabetes: Evidence for an Intrinsic Pancreatic Alpha Cell Defect. Science, 182, 171-173. https://doi.org/10.1126/science.182.4108.171

[35] Bolli, G., De Feo, P., Compagnucci, P., Cartechini, M.G., Angeletti, G., Santeusanio, F., Brunetti, P. and Gerich, J.E. (1983) Abnormal Glucose Counterregulation in Insulin-Dependent Diabetes Mellitus: Interaction of Anti-Insulin Antibodies and Impaired Glucagon and Epinephrine Secretion. Diabetes, 32, 134-141. https://doi.org/10.2337/diab.32.2.134

[36] Fukuda, M., Tanaka, A., Tahara, Y., Ikegami, H., Yamamoto, Y, Kumahara, Y. and Shima, K. (1988) Correlation between Minimal Secretory Capacity of Pancreatic Beta-cells and Stability of Diabetic Control. Diabetes, 37, 81-88. https://doi.org/10.2337/diab.37.1.81

[37] Kabadi, U.M. (1993) Hepatic Regulation of Pancreatic Alpha Cell Function. Metabolism, 42, 535-543. https://doi.org/10.1016/0026-0495(93)90208-6

[38] Banarer, S., McGregor, V.P. and Cryer, P.E. (2002) Intraislet Hyperinsulinemia Prevents the Glucagon Response to Hypoglycemia Despite an Intact Autonomic Response. Diabetes, 51, 958-965. https://doi.org/10.2337/diabetes.51.4.958

[39] Kalra, S., Mukherjee, J.J., Venkataraman, S., Bantwal, G., Shaikh, S.S., Saboo, B., et al. (2013) Hypoglycemia: The Neglected Complication. Indian Journal of Endocri- 
nology and Metabolism, 17, 819-834. https://doi.org/10.4103/2230-8210.117219

[40] Silbert, R., Salcido-Montenegro, A., Rodriguez-Gutierrez, R., Katabi, A. and McCoy, R.G. (2018) Hypoglycemia among Patients with Type 2 Diabetes: Epidemiology, Risk Factors, and Prevention Strategies. Current Diabetes Reports, 18, Article No. 53. https://doi.org/10.1007/s11892-018-1018-0

[41] Tourkmani, A.M., Alharbi, T.J., Rsheed, A.M.B., AlRasheed, A.N., AlBattal, S.M., Abdelhay, O., Hassali, M.A., Alrasheedy, A.A., Al Harbi, N.G. and Alqahtani, A. (2018) Hypoglycemia in Type 2 Diabetes Mellitus Patients: A Review Article. Diabetes \& Metabolic Syndrome: Clinical Research \& Reviews, 12, 791-794. https://doi.org/10.1016/j.dsx.2018.04.004

[42] Douglas, J.D. (1982) Exercise-Induced Hypoglycemia. Practitioner, 226, Article No. 1207.

[43] Mao, Y., Wen, S., Zhou, M., Zhu, S., Zhou, L. (2019) The Hypoglycemia Associated Autonomic Failure Triggered by Exercise in the Patients with "Brittle" Diabetes and the Strategy for Prevention. Endocrine Journal, 66, 753-762.

https://doi.org/10.1507/endocrj.EJ19-0153

[44] Cockcroft, E.J., Narendran, P. and Andrews, R.C. (2020) Exercise-Induced Hypoglycaemia in Type 1 Diabetes. Experimental Physiology, 105, 590-599. https://doi.org/10.1113/EP088219

[45] Maloney, A., Rosenstock, J. and Fonseca, V. (2019) A Model-Based Meta Analysis of 24 Antihyperglycemic Drugs for Type 2 Diabetes: Comparison of Treatment Effects at Therapeutic Doses. Clinical Pharmacology \& Therapeutics, 105, 1213-1223. https://doi.org/10.1002/cpt.1307

[46] Vaughan, E.M., Rueda, J.J., Samson, S.L. and Hyman, D.J. (2020) Reducing the Burden of Diabetes Treatment: A Review of Low-Cost Oral Hypoglycemic Medications. Current Diabetes Reviews, 16, 851-858. https://doi.org/10.2174/1573399816666200206112318

[47] Iqbal, A. and Heller, S. (2016) Managing Hypoglycaemia. Best Practice \& Research Clinical Endocrinology \& Metabolism, 30, 413-430.

https://doi.org/10.1016/j.beem.2016.06.004

[48] Heller, S.R., Amiel, S.A. and Mansell, P. (1999) Effect of the Fast-Acting Insulin Analog Lispro on the Risk of Nocturnal Hypoglycemia during Intensified Insulin Therapy. U.K. Lispro Study Group. Diabetes Care, 22, 1607-1611. https://doi.org/10.2337/diacare.22.10.1607

[49] Brunelle, B.L., Llewelyn, J., Anderson Jr., J.H., Gale, E.A. and Koivisto, V.A. (1998) Meta-Analysis of the Effect of Insulin Lispro on Severe Hypoglycemia in Patients with Type 1 Diabetes. Diabetes Care, 21, 1726-1731.

https://doi.org/10.2337/diacare.21.10.1726

[50] Home, P.D., Lindholm, A., Hylleberg, B. and Round, P. (1998) Improved Glycemic Control with Insulin Aspart. UK Insulin Aspart Study Group. Diabetes Care, 21, 1904-1909. https://doi.org/10.2337/diacare.21.11.1904

[51] Ratner, R.E., Hirsch, I.B., Neifring, J.L., Garg, S.K., Mecca, T.E. and Wilson, C.A (2000) Less Hypoglycemia with Insulin Glargine in Intensive Insulin Therapy for Type 1 Diabetes. U.S. Study Group of Insulin Glargine in Type 1 Diabetes. Diabetes Care, 23, 639-643. https://doi.org/10.2337/diacare.23.5.639

[52] Yki-Järvinen, H., Dressler, A. and Ziemen, M. (2000) Less Nocturnal Hypoglycemia and Better Post-Dinner Glucose Control with Bedtime Insulin Glargine Compared with Bedtime NPH Insulin during Insulin Combination Therapy in Type 2 Diabetes. The HOE 901/3002 Study Group. Diabetes Care, 23, 1130-1136. 
https://doi.org/10.2337/diacare.23.8.1130

[53] Hermansen, K., Madsbad, S., Perrild, H., Kristensen, A. and Axelsen, M. (2001) Comparison of the Soluble Basal Insulin Analog Insulin Detemir with NPH Insulin. Diabetes Care, 24, 296-301. https://doi.org/10.2337/diacare.24.2.296

[54] Brunson, S.A. (2007) Nocturnal Hypoglycemia: Answering the Challenge with LongActing Insulin Analogs. Medscape General Medicine, 9, Article No. 38.

[55] Kabadi, U.M. (2016) Better Glycemic Control with Lesser Hypoglycemia on Transition of Insulin Glargine Administration at Bedtime to Morning in Type 2 Diabetes Mellitus. Diabetes Research and Metabolism, 2, 1-7.

[56] Hampton, N., Exley, S., Robbins, S. and Kabadi, U.M. (2018) Lower Daily Dose with Better Outcomes with Oral Agents and AM Insulin Toujeo Administration than Lantus While Attaining Desirable Glycemic Control in Type 2 Diabetes. European Journal of Pharmaceutical and Medical Research, 5, 555-563.

[57] Shorr, R.I., Ray, W.A., Daugherty, J.R. and Griffin, M.R. (1996) Individual Sulfonylureas and Serious Hypoglycemia in Older People. Journal of the American Geriatrics Society, 44, 751-755. https://doi.org/10.1111/j.1532-5415.1996.tb03729.x

[58] Saloranta, C, Hershon, K., Ball, M., Dickinson, S. and Holmes, D. (2002) Efficacy and Safety of Nateglinide in Type 2 Diabetic Patients with Modest Fasting Hypoglycemia. Journal of Clinical Endocrinology \& Metabolism, 87, 4171-4176. https://doi.org/10.1210/jc.2002-020068

[59] McCoy, R.G., Lipska, K.J., Yao, X., Ross, J.S., Montori, V.M. and Shah, N.D. (2016) Intensive Treatment and Severe Hypoglycemia among Adults with Type 2 Diabetes. JAMA Internal Medicine, 176, 969-978. https://doi.org/10.1001/jamainternmed.2016.2275

[60] Malians, S. and Kotwal, A. (2017) Frequency and Predictors of Self-Reported Hypoglycemia in Insulin-Treated Diabetes. Journal of Diabetes Research, 2017, Article ID: 7425925. https://doi.org/10.1155/2017/7425925

[61] Freeland, B. (2017) Hypoglycemia in Diabetes Mellitus. Home Healthcare Now, 35, 414-419. https://doi.org/10.1097/NHH.0000000000000584

[62] Frier, B.M. (2014) Hypoglycaemia in Diabetes Mellitus: Epidemiology and Clinical Implications. Nature Reviews Endocrinology, 10, 711-722.

https://doi.org/10.1038/nrendo.2014.170

[63] Ahmad, I., Zelnick, L.R., Batacchi, Z., Robinson, N., Dighe, A., Manski-Nankervis, J.E., Furler, J., Neal, D.N., Little, R., Trence, D., Hirsch, I.B., Bansal, N. and de Boer, I.H. (2019) Hypoglycemia in People with Type 2 Diabetes and CKD. Clinical Journal of the American Society of Nephrology, 14, 844-853. https://doi.org/10.2215/CJN.11650918

[64] Clarke, W.L., Gonder-Frederick, L.A., Richards, F.E. and Cryer, P.E. (1991) Multifactorial Origin of Hypoglycemic Symptom Awareness in Insulin Dependent Diabetes Mellitus. Diabetes, 40, 680-685. https://doi.org/10.2337/diab.40.6.680

[65] Hepburn, D.A., Patrick, A.W., Brash, H.M., Thomson, L. and Frier, B.M. (1991) Hypoglycemia Unawareness in Type 1 Diabetes: A Lower Plasma Glucose Is Required to Stimulate Sympathoadrenal Activation. Diabetic Medicine, 8, 934-945. https://doi.org/10.1111/j.1464-5491.1991.tb01533.x

[66] Meyer, C., Grobman, R., Mitrakou, A., Mahler, R., Veneman, T., Gerich, J. and Bretzel, R.G. (1998) Effects of Autonomic Neuropathy on Counterregulation and Awareness of Hypoglycemia in Type 1 Diabetic Patients. Diabetes Care, 21, 1960-1966. https://doi.org/10.2337/diacare.21.11.1960 
[67] Korytkowski, M.T., Mokan, M., Veneman, T.F., Mitrakou, A., Cryer, P.E. and Gerich, J.E. (1998) Reduced $\beta$-Adrenergic Sensitivity in Patients with Type 1 Diabetes and Hypoglycemia Unawareness. Diabetes Care, 21, 1939-1943. https://doi.org/10.2337/diacare.21.11.1939

[68] Jones, T.W., Porter, P., Sherwin, R.S., Davis, E.A., O’Leary, P., Frazer, F., Byrne, G., Stick, S. and Tamborlane, W.V. (1998) Decreased Epinephrine Responses to Hypoglycemia during Sleep. New England Journal of Medicine, 338, 1657-1662. https://doi.org/10.1056/NEJM199806043382303

[69] Ovalle, F., Fanelli, C.G., Paramore, D.S., Hershey, T., Craft, S. and Cryer, P.E. (1998) Brief Twice-Weekly Episodes of Hypoglycemia Reduce Detection of Clinical Hypoglycemia in Type 1 Diabetes Mellitus. Diabetes, 47, 1472-1479. https://doi.org/10.2337/diabetes.47.9.1472

[70] Cryer, P.E. (2001) Hypoglycemia-Associated Autonomic Failure in Diabetes. American Journal of Physiology, 281, E1115-E1121. https://doi.org/10.1152/ajpendo.2001.281.6.E1115

[71] Szadkowska, A., Czyżewska, K., Pietrzak, I., Mianowska, B., Jarosz-Chobot, P. and Myśliwiec, M. (2018) 4 Hypoglycaemia Unawareness in Patients with Type 1 Diabetes. Pediatric Endocrinology Diabetes and Metabolism, 24, 126-134. https://doi.org/10.5114/pedm.2018.80994

[72] Cranston, I., Lomas, J., Maran, A., Macdonald, I. and Amiel, S.A. (1994) Restoration of Hypoglycaemia Awareness in Patients with Long-Duration Insulin-Dependent Diabetes. Lancet, 344, 283-287. https://doi.org/10.1016/S0140-6736(94)91336-6

[73] Pedersen-Bjergaard, U., Agerholm-Larsen, B., Pramming, S., Houghgaard, P. and Thorsteinsson, B. (2001) Activity of Angiotensin-Converting Enzyme and Risk of Severe Hypoglycemia in Type 1 Diabetes Mellitus. Lancet, 357, 1248-1253. https://doi.org/10.1016/S0140-6736(00)04405-6

[74] Bolli, G.B. (1998) Prevention and Treatment of Hypoglycaemia Unawareness in Type 1 Diabetes Mellitus. Acta Diabetologica, 35, 183-193. https://doi.org/10.1007/s005920050129

[75] Bolli, G.B. (1999) How to Ameliorate the Problem of Hypoglycemia in Intensive as Well as Nonintensive Treatment of Type 1 Diabetes. Diabetes Care, 22, B43-B52.

[76] McGowan, K., Thomas, W. and Moran, A. (2002) Spurious Reporting of Nocturnal Hypoglycemia by CGMS in Patients with Tightly Controlled Type 1 Diabetes. Diabetes Care, 25, 1499-1503. https://doi.org/10.2337/diacare.25.9.1499

[77] Tamborlane, W.V., Beck, R.W., Bode, B.W., Buckingham, B., Chase, H.P., Clemons, R., et al. (2008) Continuous Glucose Monitoring and Intensive Treatment of Type 1 Diabetes. New England Journal of Medicine, 359, 1464-1476. https://doi.org/10.1056/NEJMoa0805017

[78] Noh, R.M., Graveling, A.J. and Frier, B.M. (2011) Medically Minimising the Impact of Hypoglycemia in Type 2 Diabetes: A Review. Expert Opinion on Pharmacotherapy, 12, 2161-2175. https://doi.org/10.1517/14656566.2011.589835

[79] Unger, J. and Parkin, C. (2011) Recognition, Prevention, and Proactive Management of Hypoglycemia in Patients with Type 1 Diabetes Mellitus. Postgraduate Medicine, 123, 71-80. https://doi.org/10.3810/pgm.2011.07.2306

[80] Cornelis, A., van Beers, J., Hans DeVries, J., Kleijer, S.J., Smits, M.M., GeelhoedDuijvestijn, P.H., Kramer, M.H.H., Diamant, M. and Serné, E.H. (2016) Continuous Glucose Monitoring for Patients with Type 1 Diabetes and Impaired Awareness of Hypoglycaemia (IN CONTROL): A Randomised, Open-Label, Crossover Trial. Lancet Diabetes \& Endocrinology, 4, 893-902. 
https://doi.org/10.1016/S2213-8587(16)30193-0

[81] Lucidi, P., Porcellati, F., Bolli, G.B. and Fanelli, C.G. (2018) Prevention and Management of Severe Hypoglycemia and Hypoglycemia Unawareness: Incorporating Sensor Technology. Current Diabetes Reports, 18, Article No. 83. https://doi.org/10.1007/s11892-018-1065-6

[82] Wilson, L.M. and Castle, J.R. (2018) Stable Liquid Glucagon: Beyond Emergency Hypoglycemia Rescue. Journal of Diabetes Science and Technology, 12, 847-853. https://doi.org/10.1177/1932296818757795

[83] Pontiroli, A.E. and Ceriani, V. (2018) Intranasal Glucagon for Hypoglycaemia in Diabetic Patients. An Old Dream Is Becoming Reality? Diabetes, Obesity and Metabolism, 20, 1812-1816. https://doi.org/10.1111/dom.13317

[84] Chabenne, J.R., Mroz, P.A, Mayer, J.P. and DiMarchi, R.D. (2020) Structural Refinement of Glucagon for Therapeutic Use. Journal of Medicinal Chemistry, 63, 3447-3460. https://doi.org/10.1021/acs.jmedchem.9b01493

[85] Borden, T.J., Baker, D.E., Levien, T.L. and Gates, B.J. (2020) Newly Approved Novel Dosage Forms of Glucagon for Management of Severe Hypoglycemia. The Senior Care Pharmacist, 35, 176-181. https://doi.org/10.4140/TCP.n.2020.176

[86] Leinwand, B., Johnsrud, M., Nguyen, A., Meyer, J. and Johnson, K. (2020) A Readyto-Use Liquid Glucagon for Treatment of Severe Hypoglycemia Demonstrates Reduced Healthcare Payer Costs in a Budget Impact Model. Journal of Medical Economics, 23, 744-750. https://doi.org/10.1080/13696998.2020.1742131

[87] Rabinovich, A. and Priefer, R. (2021) Glucagon Delivery-An Overview of Current and Future Devices. Diabetes \& Metabolic Syndrome: Clinical Research \& Reviews, 15, Article ID: 102155. https://doi.org/10.1016/j.dsx.2021.05.028

[88] Kalergis, M., Schiffrin, A., Gougeon, R., Jones, P.J.H. and Yale, J.-F. (2003) Impact of Bedtime Snack Composition on Prevention of Nocturnal Hypoglycemia in Adults with Type 1 Diabetes Undergoing Intensive Insulin Management Using Lispro Insulin before Meals: A Randomized, Placebo-Controlled, Crossover Trial. Diabetes Care, 26, 9-15. https://doi.org/10.2337/diacare.26.1.9

[89] Wiethop, B.V. and Cryer, P.E. (1993) Alanine and Terbutaline in Treatment of Hypoglycemia in IDDM. Diabetes Care, 16, 1131-1136. https://doi.org/10.2337/diacare.16.8.1131

[90] Richardson, T., Thomas, P., Ryder, J. and Kerr, D. (2005) Influence of Caffeine on Frequency of Hypoglycemia Detected by Continuous Interstitial Glucose Monitoring System in Patients with Long-Standing Type 1 Diabetes. Diabetes Care, 28, 1316-1320. https://doi.org/10.2337/diacare.28.6.1316

[91] Kabadi, U.M. (1986) Nutritional Therapy in Diabetes. Postgraduate Medicine, 79, 145-156. https://doi.org/10.1080/00325481.1986.11699428 